\title{
Allergenic components of the mRNA-1273 vaccine for COVID-19: possible involvement of polyethylene glycol and IgG-mediated complement activation
}

\author{
Ludger Klimek ${ }^{1}$, Natalija Novak ${ }^{2}$, Beatriz Cabanillas ${ }^{2}$, Marek Jutel ${ }^{3}$, Jean Bousquet ${ }^{4}$, and \\ Cezmi Akdis ${ }^{5}$ \\ ${ }^{1}$ Zentrum für Rhinologie und Allergologie \\ ${ }^{2}$ University of Bonn \\ ${ }^{3}$ Wrocław Medical University \\ ${ }^{4}$ Université Versailles, St-Quentin-en-Yvelines \\ ${ }^{5}$ University of Zurich
}

January 1, 2021

\begin{abstract}
Following the emergency use authorization of the vaccine mRNA-1273 on 18th December 2020 in the US and the vaccine BNT162b2 one week earlier, two mRNA vaccines are in currently used for the prevention of coronavirus disease 2019 (COVID19). Phase 3 pivotal trials on both vaccines excluded individuals with a history of allergy to vaccine components. Immediately after the initiation of vaccination in the United Kingdom, Canada, and in the US, anaphylactic reactions have been reported. While the culprit trigger requires investigation, initial reports suggested the excipient polyethylene glycol 2000 (PEG-2000), which is contained in both vaccines as PEG-micellar carrier system as the potential culprit. Surface PEG chains form a hydrate shell to increase stability and prevent opsonization. Allergic reactions to such PEG-ylated lipids are rarely IgEmediated, but may result from complement activation-related pseudoallergy (CARPA) that has been described to similar liposomes. In addition, mRNA-1273 also contains tromethamine (trometamol), which has been reported to cause anaphylaxis to e.g. gadolinium-based or iodinated contrast media. Skin prick-, intradermal-, epicutaneous- tests, in vitro sIgE assessment, evaluation of $\operatorname{sgG} / \operatorname{IgM}$, as well as basophil activation test are in use to demonstrate allergic reactions to various components of the vaccines.
\end{abstract}

\section{Hosted file}

Potential allergenic components of Moderna vaccine for COVID-19_per 29122020 corrections CA and MJ fi. available at https://authorea.com/users/327586/articles/502049-allergenic-components-of-themrna-1273-vaccine-for-covid-19-possible-involvement-of-polyethylene-glycol-and-igg-

mediated-complement-activation 
Moderna vaccine for COVID-19 (mRNA-1273)

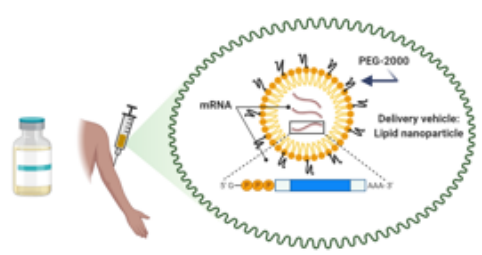

Potential allergic triggers in

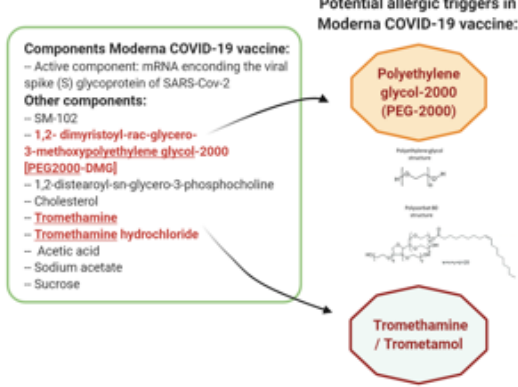

Allergic reaction due to PEG contained in drugs, intravenous substances, food additives, and other products

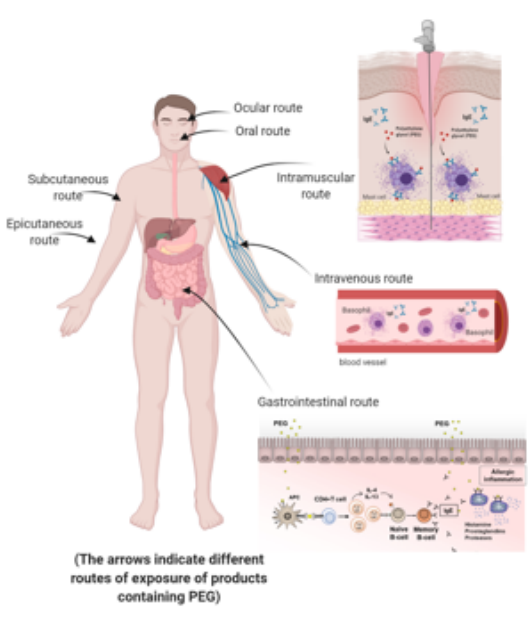

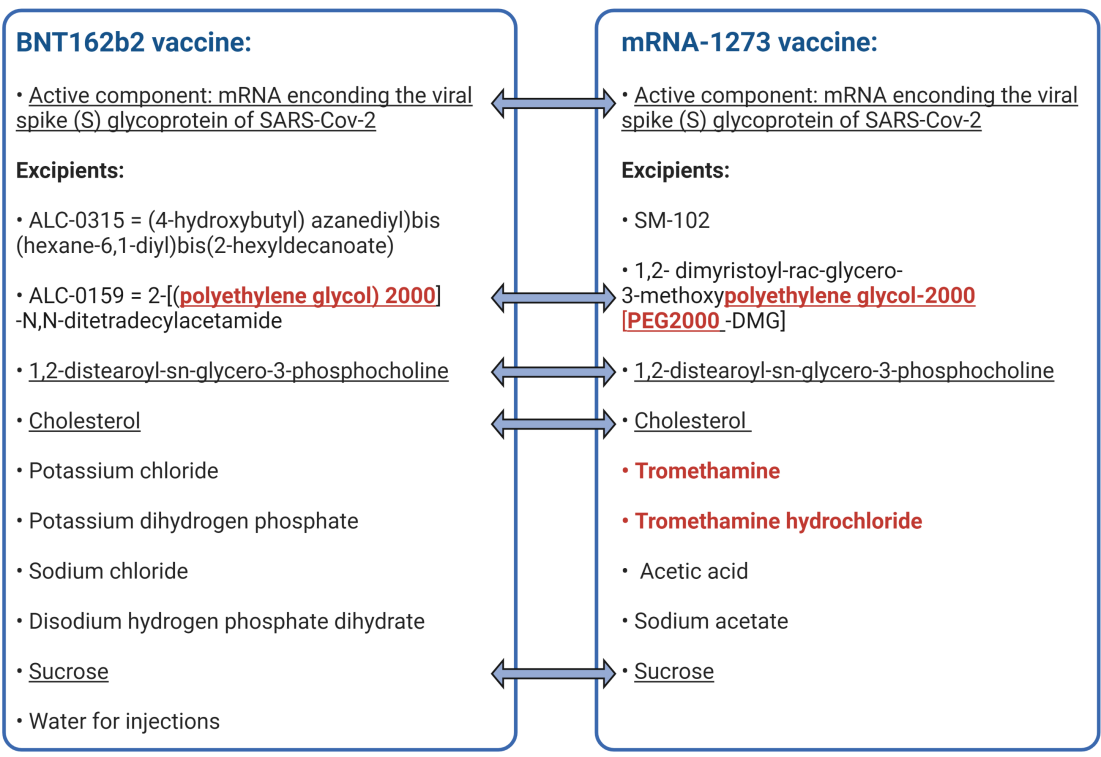

